\title{
Unlocking the mysteries of the ice ages
}

\author{
Maureen E. Raymo \& Peter Huybers
}

\section{Much progress has been made towards understanding what caused the waxing and the waning of the great ice sheets, but a complete theory of the ice ages is still elusive.}

Perhaps the longest-standing puzzle in the Earth sciences is what caused the Northern Hemisphere ice sheets to come and go. Earth scientists have been trying to solve this puzzle since 1840, when Louis Agassiz proposed that the geological deposits in Europe and North America were the remnants of vast ice sheets that spilled from the mountains.

Joseph Adhémar seems to have been the first to suggest that glaciation was associated with changes in the configuration of Earth's orbit relative to the Sun. In 1842, he proposed that glaciation occurs when winters are anomalously long, which happens when they coincide with aphelion (the point of Earth's orbit that is farthest from the Sun). James Croll subsequently argued in the 1860s that glaciation occurs when winters coincide with aphelion not because such winters are longer but because the intensity of insolation (that is, solar radiation) is weaker at this point. At present, the favoured hypothesis is that proposed by Milutin Milanković, who turned Croll's argument on its head in the 1930s. He argued that glaciation occurs when insolation intensity is weak at high northern latitudes during summer. This happens when both Earth's spin axis is less tilted with respect to the orbital plane and aphelion coincides with summer (not winter) in the Northern Hemisphere. According to Milanković, when there is less insolation during the summer, snow and ice persist through the year, gradually accumulating into an ice sheet.

In 1976, James Hays, John Imbrie and Nicholas Shackleton ${ }^{1}$ unearthed strong evidence in support of the orbital hypothesis of glaciation. Applying the newly developed geomagnetic timescale to a deep-sea sediment core, they showed that long-term variations in oxygen isotope ratios, as recorded in fossils of foraminifera, were concentrated at the frequencies predicted by the orbital hypothesis. The ratio of oxygen- 18 to oxygen-16 $\left(\delta^{18} \mathrm{O}\right)$ in the ocean was known to increase with glaciation, because oxygen-16 evaporates preferentially and is concentrated in ice sheets. Hays et al. ${ }^{1}$ showed that $\delta^{18} \mathrm{O}$ varied with cycles of 41,000 years, the period associated with changes in the tilt of Earth's spin axis (or obliquity), and around 21,000 years, the period associated with the location of aphelion with respect to the seasons (also known as climatic precession or the precession of the equinoxes). But other questions immediately arose. The authors also found that, during the past 800,000 years, ice sheets took about 90,000 years to grow and only 10,000 years to collapse. They proposed a link with the eccentricity of Earth's orbit, which varies at periods of about 100,000 years. Earth's eccentricity has only a weak effect on incoming solar radiation, however, so the strong presence of a 100,000-year cycle was perplexing. Likewise, it was unclear why the rates of growth and collapse were asymmetrical.

Since this study was published, and with improvements in the dating of geological samples, strong evidence for an orbital influence on climate has been found across the globe. An understanding of how Earth's insolation has varied in the past and observations of the subsequent shifts in climate provide an opportunity to probe the mechanisms that control long-term climate change. Several hurdles must be overcome, however, before this knowledge can be used to its full potential. The climate physics and chemistry that are best understood are mainly attuned to processes that occur at daily to interannual timescales. Are the important factors that regulate climate over centennial and longer timescales known? When a climate model is stepped forward, by minutes or days at a time, for hundreds or thousands of years, are the final results realistic? Climate scientists still do not understand how the subtle shifts in insolation at the top of the atmosphere are converted into massive changes in the ice volume on the ground.

\section{Regular timing}

To tackle these problems, some researchers have turned to a time when glaciation seems to have been relatively straightforward. The glacial cycles of the late Pliocene to early Pleistocene ( $\sim 1-3$ million years ago) were more regular than those of the late Pleistocene, typically lasting about 41,000 years (Fig. 1a), which matches the period of change in Earth's tilt ${ }^{2}$ (Fig. 1b). But how is the lack of variability with respect to precession explained? Precession, which occurs mainly at 23,000-year and 19,000-year intervals, is the orbital component that most influences summer insolation intensity (Fig. 1c). Indeed, precession is clearly observed in the ice-volume and sea-level records for the past 700,000 years. The few computer models that have been used to study the climate history of the late Pliocene to early Pleistocene also show a strong precession signal in the modelled ice volume. Are these climate models missing a fundamental piece of climate or ice-sheet physics, or are the assumptions about ice-volume proxies, such as $\delta^{18} \mathrm{O}$, flawed? Both are possibilities.

One resolution to the puzzle of the missing precession variance harks back to Adhémar's proposal: summers with the greatest insolation intensity are also about a week shorter than the average duration of summer, because Earth orbits more quickly when it is close to the Sun. Peter Huybers ${ }^{3}$ proposed that the amount of melting an ice sheet undergoes is better gauged by integrating the total insolation over summer (with summer defined as the period when insolation intensity exceeds a melting threshold), as opposed to using either the peak or the mean intensity of summer insolation. This summer-energy metric varies mainly at the obliquity period and is therefore consistent with the oxygen isotope record observed in marine samples from 1-3 million years ago (Fig. 1a, b). Why, then, do ice-sheet computer models, which implicitly incorporate integrated insolation and a full seasonal cycle, show that precession is the dominant control on the amount and timing of ablation? Huybers and Eli Tziperman ${ }^{4}$ recently demonstrated that an icesheet model can generate 40,000-year glacial cycles when two conditions are met: the zone where the ice sheet is ablated must be north of about $60^{\circ} \mathrm{N}$, where changes in obliquity have a greater effect on insolation, and the summer melt season must be long enough for changes in its duration to balance changes in insolation intensity. In the model of Huybers and Tziperman, a longer melt season results from sliding at the base of the ice sheet, which thins the ice sheet and draws its surface down to lower (warmer) elevations. They proposed that these factors are responsible for the different behaviour of the earlier ice sheets.

Climate modellers, geologists and geochemists should take note. These are testable predictions that are reminiscent of the regolith hypothesis of Peter Clark and David Pollard ${ }^{5}$. To reconcile the observation of late 


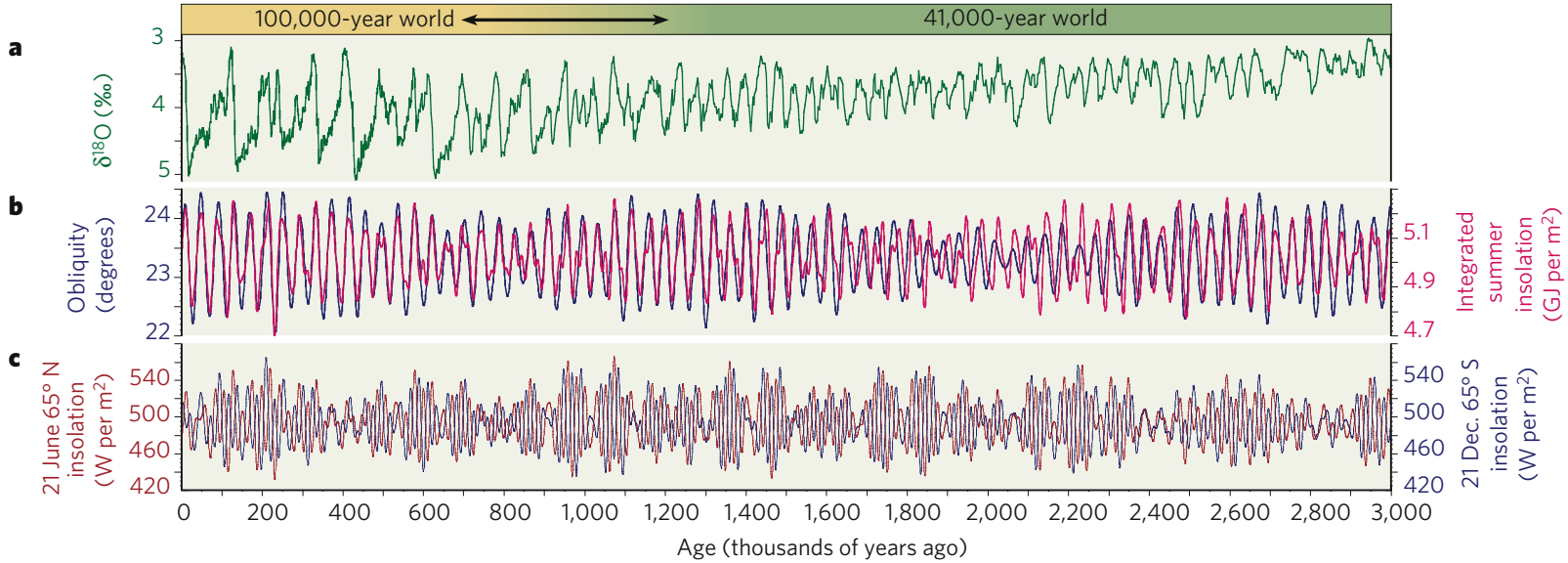

Figure 1 Ice-age climate and solar variability. A 3-million-year record of $\delta^{18} \mathrm{O}$ (ref. 8) (a); orbital obliquity (blue) compared with integrated summer insolation $(\text { red })^{3}($ b) ; and summer insolation for the Northern Hemisphere (on 21 June at $65^{\circ} \mathrm{N}$; red) and the Southern Hemisphere (on 21 December at $65^{\circ} \mathrm{S}$; blue $)^{6}(\mathrm{c}) . \delta^{18} \mathrm{O}$ is considered a proxy of global ice-volume change, which is assumed to occur mostly in the Northern Hemisphere over this

Pliocene to early Pleistocene ice-margin deposits in Iowa and Kansas (at $40^{\circ} \mathrm{N}$ ) during a time when the marine oxygen isotope record (Fig. 1a) suggests that ice sheets were smaller, Clark and Pollard proposed that a glacial substrate of easily deformable sedimentary rocks allowed basal sliding to increase and therefore resulted in a continental ice sheet that was thinner overall. They proposed that the gradual erosion of this upper sedimentary layer by ice sheets led to the transition to the larger, less mobile ice sheets of the late Pleistocene that varied at the slower 100,000year periodicity. Was the maximum extent of the ice edge typically as far south as $40^{\circ} \mathrm{N}$ between 1 and 3 million years ago? Can sedimentological and mineralogical evidence be found for a long-term change in the erosional substrate scoured by this ice sheet? How thick were the late Pliocene to early Pleistocene ice sheets on North America? Are the proposed changes in basal sliding realistic? The answers to these questions have important implications for climate models.

\section{Out of phase}

Another explanation for the lack of a precession signal in records of ice volume was proposed by Maureen Raymo, Lorraine Lisiecki and Kerim Nisancioglu ${ }^{6}$. They put forward a model in which Northern Hemisphere ice sheets wax and wane at precession periods, driven by the strongly nonlinear response of ice ablation to summer insolation intensity. In this model, however, the precession component of changes in ice volume is missing from marine records of $\delta^{18} \mathrm{O}$ because it is 'cancelled out' by changes in Southern Hemisphere ice volume that are of opposite phase. The effect of the precession of the equinoxes on summer insolation intensity is out of phase between hemispheres, whereas the effect of obliquity is in phase (Fig. 1c; look at times when precession is weak, such as $\sim 2.4$ million years ago). Thus, precession-paced changes in ice volume in each hemisphere would cancel out in globally integrated proxies such as ocean $\delta^{18} \mathrm{O}$ or sea level, leaving the in-phase obliquity (41,000-year) component of ice volume to dominate the records. Even a few tens of metres of ice-volume variance in the Southern Hemisphere would be enough to effectively hide a much greater Northern Hemisphere precession signal.

Is this possible? Could a terrestrial ice margin sensitive to local summer insolation have waxed and waned on East and West Antarctica at that time in the late Pliocene and early Pleistocene? We know little about the history of Antarctica at that time. The Antarctic Geological Drilling (ANDRILL) programme has astonished scientists recently with evidence for periodic warm open waters in the Ross Sea up until as recently as 1 million years $\mathrm{ago}^{7}$. And any evidence for a terrestrial ice margin at that time is now buried under the marine-based margin that encircles East Antarctica. To test interval. From 3 to 1 million years ago, $\delta^{18} \mathrm{O}$ varies primarily at the 41,000 year period characteristic of obliquity and integrated insolation. From 1 million years ago to the present, longer cycles of climate change, with a roughly 100,000-year period, are more obvious. The double-headed arrow indicates a transition more gradual than abrupt over the time indicated. GJ, gigajoule; $\mathrm{W}$, watts.

this idea for the origin of the '41,000-year world', well-dated proxy records sensitive to local climate and to the lateral movement of ice margins on land (in both the Northern Hemisphere and the Southern Hemisphere) are needed. Will such records show precession pacing? Similarly, Antarctic ice cores that extend into the early Pleistocene would help to determine whether, at that time, the local climate was in phase (as it is today) or out of phase with Northern Hemisphere insolation changes. Planning for such expeditions is already under way in the ice-core community. It could be that the East and West Antarctic ice sheets have had a far more dynamic history than has been thought.

It is widely accepted that variations in Earth's orbit affect glaciation, but a better and more detailed understanding of this process is needed. How can the 41,000-year glacial cycles of the early Pleistocene be explained, let alone the 100,000 -year glacial cycles of the late Pleistocene? How do the subtle changes in insolation relate to the massive changes in climate known as glacial cycles? And what are proxy climate records actually measuring? The field now faces these important questions, which are made all the more pressing as the fate of Earth's climate is inexorably tied to the vestige of Northern Hemisphere glaciation that sits atop Greenland, and to its uncertain counterpart to the south.

Maureen Raymo is in the Department of Earth Sciences, Boston University, 685 Commonwealth Avenue, Boston, Massachusetts 02215, USA. Peter Huybers is in the Department of Earth and Planetary Sciences, Harvard University, 20 Oxford Street, Cambridge, Massachusetts 02138, USA.

1. Hays, J. D., Imbrie, J. \& Shackleton, N. J. Variations in the Earth's orbit: pacemaker of the ice ages. Science 194, 1121-1131 (1976).

2. Pisias, N. G. \& Moore, T. C. The evolution of Pleistocene climate: a time series approach Earth Planet. Sci. Lett. 52, 450-458 (1981).

3. Huybers, P. J. Early Pleistocene glacial cycles and the integrated summer insolation forcing. Science 313, 508-511 (2006)

4. Huybers P. J. \& Tziperman, E. Integrated summer insolation forcing and 40,000 year glacial cycles: the perspective from an icesheet/energy balance model. Paleoceanography (in the press).

5. Clark, P. U. \& Pollard, D. Origin of the middle Pleistocene transition by ice sheet erosion of regolith. Paleoceanography 13,1-9 (1998).

6. Raymo, M. E., Lisiecki, L. \& Nisancioglu, K. Plio-Pleistocene ice volume, Antarctic climate, and the global $\delta^{18} O$ record. Science $313,492-495$ (2006)

7. Naish, T., Powell, R., Levy, R. \& the ANDRILL-MIS Science Team. Examining Antarctica. Geotimes 30-33 (October 2007)

8. Lisiecki, L. E. \& Raymo, M. E. A Plio-Pleistocene stack of 57 globally distributed benthic $\delta^{18} \mathrm{O}$ records. Paleoceanography 20, PA1003 (2005)

Acknowledgements This work was supported by the National Science Foundation.

Author Information Reprints and permissions information is available at npg.nature.com/reprints. Correspondence should be addressed to M.E.R. (raymo@bu.edu). 